\title{
Aluminum Clad Spent Nuclear Fuel Task 2: Oxide Layer Radiolytic Gas Generation Resolution Experiment Test Plan
}

Peter Zalupski

July 2018

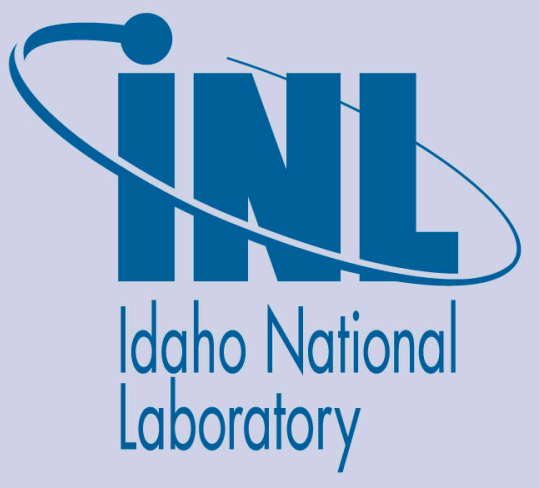

The INL is a U.S. Department of Energy National Laboratory operated by Battelle Energy Alliance 


\section{DISCLAIMER}

This information was prepared as an account of work sponsored by an agency of the U.S. Government. Neither the U.S. Government nor any agency thereof, nor any of their employees, makes any warranty, expressed or implied, or assumes any legal liability or responsibility for the accuracy, completeness, or usefulness, of any information, apparatus, product, or process disclosed, or represents that its use would not infringe privately owned rights. References herein to any specific commercial product, process, or service by trade name, trade mark, manufacturer, or otherwise, does not necessarily constitute or imply its endorsement, recommendation, or favoring by the U.S. Government or any agency thereof. The views and opinions of authors expressed herein do not necessarily state or reflect those of the U.S. Government or any agency thereof. 


\title{
Aluminum Clad Spent Nuclear Fuel Task 2: Oxide Layer Radiolytic Gas Generation Resolution Experiment Test Plan
}

\author{
Peter Zalupski
}

July 2018

Idaho National Laboratory Idaho Falls, Idaho 83415

http://www.inl.gov

\section{Prepared for the}

U.S. Department of Energy Office of Environmental Management Under DOE Idaho Operations Office Contract DE-AC07-05ID14517 



\section{Aluminum Clad Spent Nuclear Fuel Task 2: Oxide Layer Radiolytic Gas Generation Resolution Experiment Test Plan}

INL/EXT-18-45858

July 2018

Prepared by:

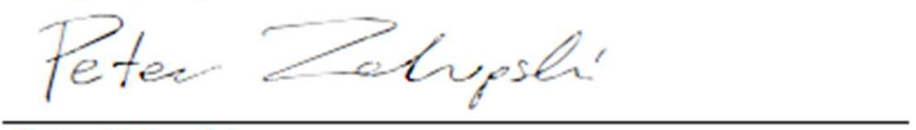

Peter Zalupski

$07 / 23 / 2018$

Date

Approved by:

Postrua Yarull

$07 / 23 / 2018$

Josh Jarrell

INL Integration Lead

Date

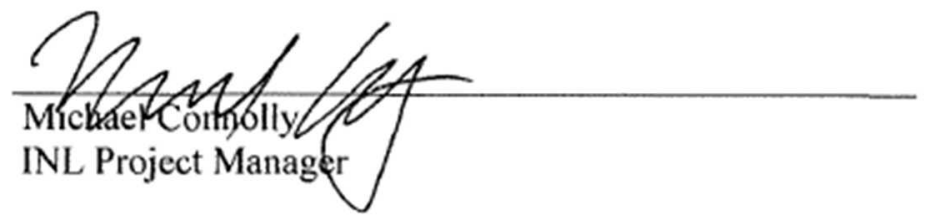

$8 / 30 / 2018$ Date 



\section{SUMMARY}

This document presents the test plan for Task 2 of the Aluminum Clad Spent Nuclear Fuel Long Term Dry Storage Technical Issues Action Plan. This task's overarching goal is the resolution of gas generation resulting from the radiolytic degradation of the oxide layers on aluminum. The uncertainty associated with the build-up of gaseous radiolytic products inside the ASNF storage canisters is one of the dominant technical challenges associated with long term dry storage of aluminum clad fuel.

The objectives of the Task 2 test plan are to:

1. Understand how radiation chemistry inside the ASNF dry storage canister impacts extended dry storage performance.

2. Understand the radiation induced mechanisms governing the production of radiolytic gases and alteration of gas composition within a canister.

3. Correlate the observed changes in material properties of ASNF with the radiolytic degradation of aluminum oxide in fill environments of variable moisture and gas composition.

4. Compile a predictive kinetic modeling tool, to provide quantitative mechanistic insight into the in-cask radiation chemistry of ASNF.

5. Interface with the canister modeling activity of Task 3 to deliver degradation rates for package performance of both sealed and vented scenarios. 


\section{CONTENTS}

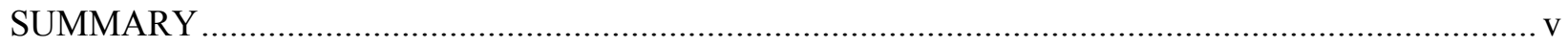

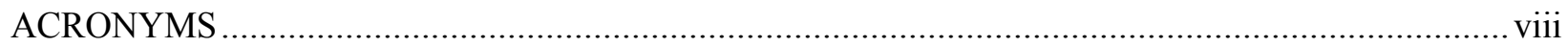

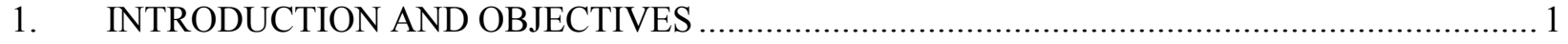

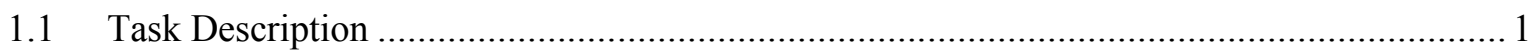

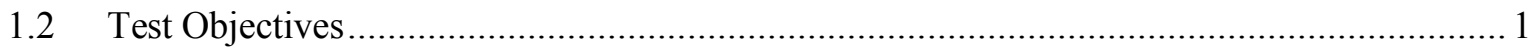

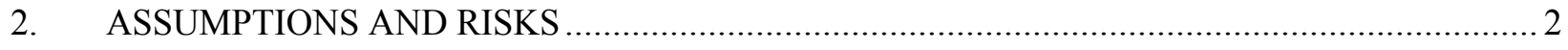

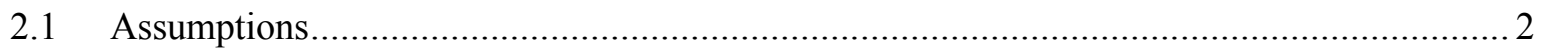

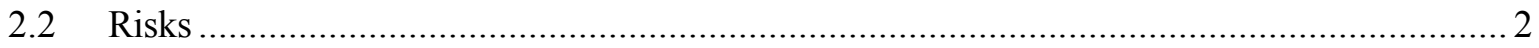

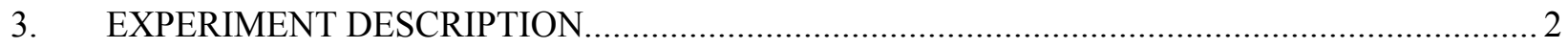

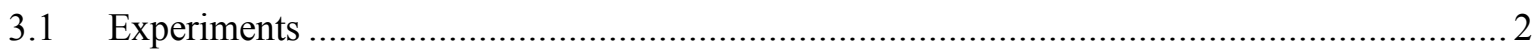

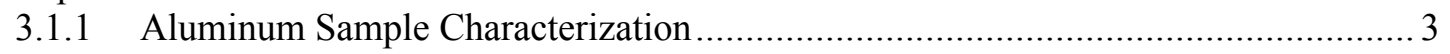

3.1.2 Aluminum Alloy Specimen Conditioning....................................................... 3

3.1.3 Preparation of Sealed Irradiation Vessels ........................................................... 3

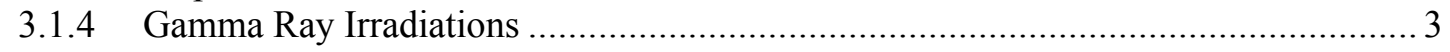

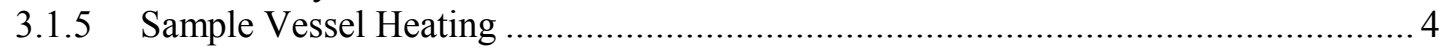

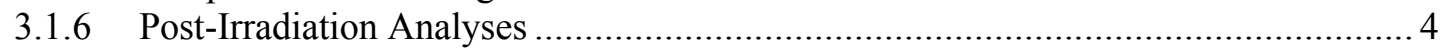

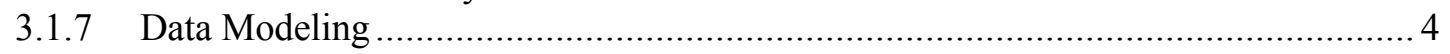

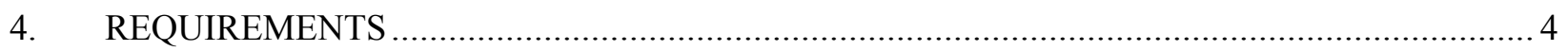

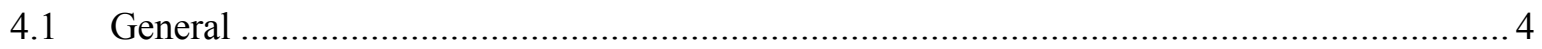

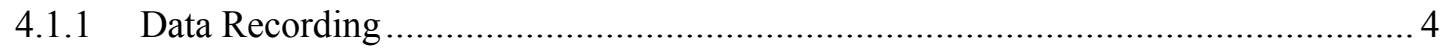

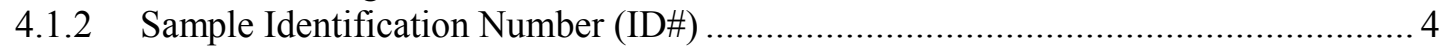

4.1.3 Recording Time for Experiments ............................................................. 4

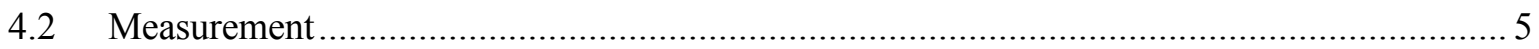

4.2.1 Use of Balances for Recording Mass …......................................................... 5

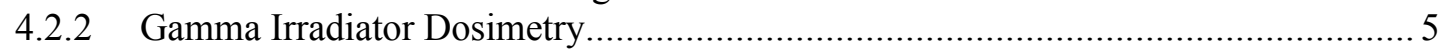

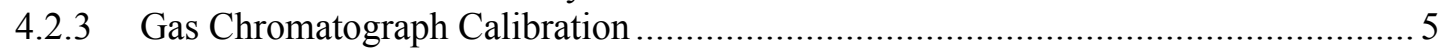

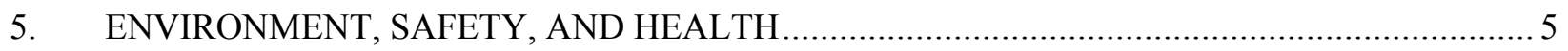

6. QUALITY ASSURANCE AND DATA/RECORD MANAGEMENT …................................ 5

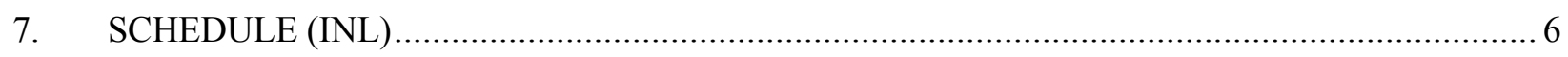

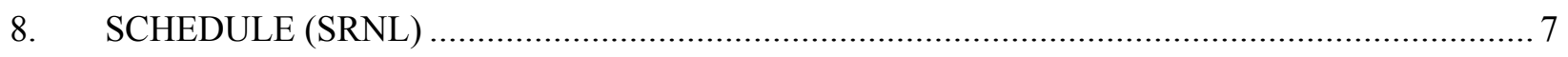

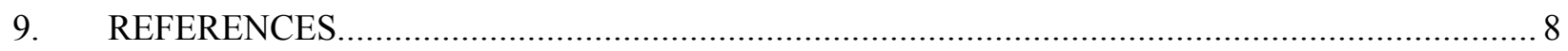




\section{ACRONYMS}

$\begin{array}{ll}\text { Al } & \text { aluminum } \\ \text { ASNF } & \text { aluminum-clad spent nuclear fuel } \\ \text { DOE } & \text { Department of Energy } \\ \text { GC } & \text { gas chromatography } \\ \text { OHO } & \text { oxyhydroxide }\end{array}$




\title{
Aluminum Clad Spent Nuclear Fuel Task 2: Oxide Layer Radiolytic Gas Generation Resolution Experiment Test Plan
}

\author{
1. INTRODUCTION AND OBJECTIVES
}

Aluminum-clad spent nuclear fuel (ASNF), when placed in interim storage, is subject to a combination of thermal, chemical, and radiolytic corrosion [1,2]. The combination of thermal, chemical, and radiolytic corrosion negatively effects the physical and chemical properties of the aluminum cladding, ultimately compromising its integrity. Furthermore, radiolytic gas generation [3,4], particularly molecular hydrogen $\left(\mathrm{H}_{2}\right)$ [5,6], and nitric acid $\left(\mathrm{HNO}_{3}\right)$ [7-9] leads to pressurization [10] and subsequent physical stresses and embrittlement [11-13] of the aluminum cladding, chemical corrosion, and the potential for flammable and explosive gas mixture formation. The thermal and chemical corrosion of aluminum is well established [2], whereas radiolytic effects are comparatively in their infancy. To evaluate the feasibility of long term storage of ASNF ( $>50$ years) a comprehensive "blueprint" of chemical reactions occurring inside a fuel canister is needed. Radiolysis of all system components (aluminum cladding, oxyhydroxide layers (OHO), stainless steel canister, and in-canister gaseous environment) drives all degradation pathways, and is critical to accurate representation (and projection) of in-canister conditions.

\subsection{Task Description}

Task 2 will study the radiolysis of the oxide/oxyhydroxide layers present on the surfaces of aluminum and the associated production of gases within the storage canister. This task will answer the following questions:

- What important gases (e.g., $\mathrm{H}_{2}$, oxygen, and $\mathrm{NO}_{\mathrm{x}}$ ) are produced inside ASNF canisters?

- What are the rates of radiolytic gas generation?

- What are the radiolytic degradation mechanisms?

Fundamentally, this task will support storage models (Task 3) with information about maximum gas generation rates.

\subsection{Test Objectives}

Experimental work will investigate the radiation chemistry of aluminum oxyhydroxides in both powder form and as a film adhered to aluminum-based alloys. The resultant radiolytic gas mixtures and post-irradiation oxide properties will be evaluated as a function of temperature, atmosphere gas composition and pressure, humidity, absorbed gamma dose, aluminum alloy, and OHO layer thickness representative of conditions expected in dry storage for both vented and non-vented scenarios. The following research outcomes are anticipated as a result of testing:

- The collection of radiolytic yields (G-values) and concentration dependencies for potentially problematic and corrosive gases (e.g. $\mathrm{H}_{2}$ and $\mathrm{NO}_{\mathrm{x}}$ ) as a function of all key parameters influencing radiolytic gas generation.

- Estimation of impact of radiolytic damage on aluminum alloys.

- Mechanistic explanation of radiolytic gas generation.

- A predictive kinetic modeling tool, providing quantitative mechanistic insight into the in-cask radiation chemistry of ASNF.

The findings from this work will address the DOE's concern for extended dry storage of ASNF and outline a coherent understanding for the radiation induced corrosion of aluminum metal. 


\section{ASSUMPTIONS AND RISKS \\ 2.1 Assumptions}

It is assumed that the ranges chosen for the experimental parameter matrix will represent actual incanister atmospheres for vented and sealed systems.

\subsection{Risks}

The accuracy of representing actual in-cask environment and its chemistry dominates the risk assessment. While the experimental data collected on aluminum clad fuel after in-reactor service exists, the conditions of the used fuel inside the cask are not monitored. Accordingly, the predictions of in-cask environment (gaseous composition, temperature, pressure) are based on empirical estimations. Task 2 activities will generate a mechanistic understanding of gas generation resulting from radiation induced corrosion of aluminum for a broad range of scenarios (temperature, radiation dose, in-canister fill composition, humidity). This comprehensive radiation chemistry blueprint will be applied explicitly once a more accurate knowledge of in-cask conditions is determined by the concurrent ASNF research activities.

\section{EXPERIMENT DESCRIPTION}

In general, the Task 2 research activities will track the evolution of gaseous products inside closed systems containing aluminum specimens. The gas generation will be monitored as the sealed systems are subjected to gamma radiation. It is foreseen such radiolytic trends will vary with: (1) temperature, (2) atmosphere, (3) humidity, (4) dose, (5) aluminum alloy, and (6) oxyhydroxide corrosion layer morphology and thickness. All six variables will be tested to develop a thorough understanding of radiolytic gas generation. The experimental ranges for the 6 parameters are:

1. Temperature: $25,50,75,100$ and $150^{\circ} \mathrm{C}$.

2. Atmosphere: Air, $\mathrm{He}, \mathrm{N}_{2}, \mathrm{~N}_{2} \mathrm{O}$.

3. Humidity: 0, 25, 50, 75 and $100 \%$.

4. Dose: $0,250,500,750,1000,2000$, and $3000 \mathrm{kGy}$.

5. Aluminum alloy: 6061,1100 .

6. Corrosion layer thickness: $1,3,6 \mu \mathrm{m}$ if feasible.

All conditions will be tested in triplicate.

Aluminum specimens to be tested will take two forms; pure Boehmite/Gibbsite powders, and labgrown adhered oxyhydroxide films on aluminum alloy coupons. Powder testing will provide radiolysis rate effects of grain size, high sample loading concentrations, and will likely generate and validate bounding G-values for simple theoretical systems. Oxyhydroxide layered samples will in turn provide rate determination for more realistic conditions with a dependence on oxide thickness and film properties. Detailed material characterization of underlying aluminum specimens will also be performed to relate structural changes (corrosion), radiolytic degradation, and gas production trends.

\subsection{Experiments}

Experiments will be performed by both INL and SRNL in order take full advantage of existing irradiation capabilities, allow for more specialized test setups for vented vs. sealed storage configurations, and to provide independent confirmation of key findings. The experiments described in the following sections are necessary to accomplish the outlined research activities. 


\subsubsection{Aluminum Sample Characterization}

\subsubsection{Scanning-Electron Microscopy}

Surface characterization, specifically the thickness of the oxyhydroxide film on the aluminum alloy specimens before and after gamma irradiation will be performed.

\subsubsection{X-ray Photoelectron Spectroscopy}

Determination of the oxidation state distribution of the alloy surface.

\subsubsection{X-ray Diffraction}

Investigation of changes in bulk structure of oxide layers (if crystalline).

\subsubsection{Particle Size Distribution}

Confirmation of Gibbsite/Boehmite powder grain size prior to testing.

\subsubsection{Aluminum Alloy Specimen Conditioning}

\subsubsection{In-house Oxyhydroxide Pre-Filming}

Fundamental tests will establish a relationship between radiolytic gas generation and the thickness of the oxyhydroxide aluminum corrosion film. The oxide layer is readily formed on the surfaces of aluminum, with growth accelerated by exposure to water, increased temperature and time of growth. Aluminum specimens will be "conditioned" in deionized water at $\mathrm{pH} 5.5-6.0$ at variable temperatures, pressures, and times to produce corrosion layers ranging from 0.5 to $3 \mu \mathrm{M}$. The oxide growth may also be enhanced due to exposure to gamma radiation. Such oxide film thickness range is not representative of corrosion typically observed on in-reactor irradiated aluminum clad fuel $(10-50 \mu \mathrm{M})$, however a fundamental correlation may be established using the in-house specimens.

\subsubsection{Hot Wall Immersion Oxyhydroxide Pre-Filming}

Fundamental studies connecting oxide thickness and radiolytic gas generation will be extended to specimens conditioned using a hot wall immersion treatment to simulate heat flux conditions during oxyhydroxide growth in-reactor. Those pre-filmed specimens will be produced at Savannah River National Laboratory, and tested at both SRNL and INL.

\subsubsection{Preparation of Sealed Irradiation Vessels}

The characterized, pre-conditioned aluminum alloy specimens will be housed in borosilicate glass tubes. The tubes will be threaded to Schlenk line ports, closing a controlled atmosphere environment. The Schlenk line will be utilized to flush and fill the vessels with an appropriate gaseous atmosphere. The humidity will be controlled through the addition of water, followed by freeze-thawing, evacuation, and filling with the required atmosphere. The glass tubes will be flame sealed prior to irradiation.

\subsubsection{Gamma Ray Irradiations}

The gamma irradiation studies will be performed using Co-60 irradiators located at SRNL and INL. INL irradiations will be performed using a MDS Nordion GammaCell 220E self-contained Co-60 gamma irradiator with center line dose of $0.824 \mathrm{~Gy} / \mathrm{sec}$ as of the $2^{\text {nd }}$ of April 2018, as determined by Fricke dosimetry. SRNL irradiation will be performed using a JL Shepherd Model 109-68 and JL Shepherd Model 484 variable dose rate irradiator with maximum dose rates of $0.256 \mathrm{~Gy} / \mathrm{sec}$ and $0.244 \mathrm{~Gy} / \mathrm{sec}$ respectively as of the $2^{\text {nd }}$ of April 2018, as determined by alanine dosimetry. Sealed irradiation vessels will be placed in an ampule holder and positioned inside the irradiator's chamber and subsequently exposed to the gamma-field. 


\subsubsection{Sample Vessel Heating}

Sample vessels selected for elevated temperature testing will be heated using heat tape/ribbon and necessary heat sinks and insulation to maintain target temperatures via thermocouples and digital temperature controllers.

\subsubsection{Post-Irradiation Analyses}

\subsubsection{Gas Chromatography}

Post-irradiation, the sample vessels' gaseous headspace will be analyzed using gas chromatography. INL will utilize a SRI 8610 model GC, and SRNL will utilize an Inficon 3000 model GC. Both instruments employ a thermal conductivity detector to discriminate and quantify gas as it elutes from the installed column. A carrier gas of ultra-high-purity argon (99.999\%) will be used for both instruments. Sample vessels will be cracked open either while directly connected to the GC or while contained in purged gas sampler designed to equilibrate pressure for optimized GC sample injections.

\subsubsection{Surface Characterization}

Per Section 3.1.1.

\subsubsection{Data Modeling}

Experimental data will be used to construct a predictive theoretical description for modeling radiation-induced gas phase chemistry inside the ASNF canister. The model will build upon established water radiolysis kinetic mechanisms $[14,15]$ and incorporate reaction kinetics for the remaining components of our investigated systems (e.g., $\mathrm{NO}_{\mathrm{x}}$ and $\mathrm{CO}_{2}$ ), providing a set of ordinary differential equations to be solved using the numerical algorithm FACSIMILE (MCPA software).

\section{REQUIREMENTS}

\subsection{General}

\subsubsection{Data Recording}

Maintain Laboratory Notebook in accordance with MCP-2875, "Proper Use and Maintenance of Laboratory Notebooks."

Protect and apply the appropriate Controlled Unclassified Information (CUI) labeling based on content's sensitivity by following the Controlled Unclassified Information Homepage. Contact a Derivative Classifier if you need assistance determining the sensitivity of a Laboratory Notebook's content.

\subsubsection{Sample Identification Number (ID\#)}

All aluminum coupons will be assigned a unique identifier (or ID\#) before use in an experiment. All sealed irradiation vessels will be assigned a unique identifier (or ID\#). Assignments will be recorded in laboratory notebooks.

\subsubsection{Recording Time for Experiments}

\subsubsection{Start, Sampling, and Stop Times}

All time stamps will be recorded in laboratory notebooks. The accuracy of the irradiator time clocks will be verified. 


\subsection{Measurement}

When possible, calibrated instruments will be used. The person performing the experiment should record calibration specific information including calibration numbers and calibration due date.

\subsubsection{Use of Balances for Recording Mass}

All balances used will be within the calibration date (label on balance). Record calibration due date in notebook.

\subsubsection{Gamma Irradiator Dosimetry}

Gas phase dosimetry for all vessel configurations used during irradiation experiments will be performed prior to the beginning of studies. All calibration data will be recorded in the laboratory notebook.

\subsubsection{Gas Chromatograph Calibration}

The gas chromatographs will be calibrated using $\mathrm{H}_{2}, \mathrm{O}_{2}$, and $\mathrm{N}_{2}$ standards.

\section{ENVIRONMENT, SAFETY, AND HEALTH}

The test plan will be executed at both INL and SRNL. INL testing will be performed at the REC facility: Energy Innovation Laboratory (EIL) and if needed at MFC facility: Fuel Assembly Building (FASB). The activities will be performed under two Laboratory Instructions (LI). Aluminum coupon prefilming with oxyhydroxide film will be performed under LI-697, "Chemical Synthesis and Characterization for Aqueous Separations." Gamma irradiations and GC analyses will be performed under LI-868, "Radiation Chemistry Research." All requirements are contained within the appropriate LI.

SRNL testing will be performed at the Gamma Irradiation Facility. Work instructions and hazard analyses for the work fall under SRNL-ACT-0585, "Radiolysis of Aluminum Oxyhydroxide," SRNLL4400-2016-00028-1, "Operation of Gamma Irradiation Units," and SRNL-L4000-2010-00038-5, "Glass Apparatus Lab."

\section{QUALITY ASSURANCE AND DATA/RECORD MANAGEMENT}

Quality assurance activities associated with Task 2 comply with all applicable requirements set forth in the INL Quality Assurance Program based on ASME NQA-1 2000. 
7. SCHEDULE (INL)

\begin{tabular}{|c|c|c|c|c|c|c|c|c|c|}
\hline \multirow{2}{*}{ Activity } & \multirow{2}{*}{ Description } & \multicolumn{4}{|c|}{ FY18 } & \multicolumn{4}{|c|}{ FY19 } \\
\hline & & $\mathbf{1}$ & 2 & 3 & 4 & 1 & 2 & 3 & 4 \\
\hline 2.1 & $\begin{array}{c}\text { Experimental design: vessel / gas sampling / bounding conditions } \\
\text { and material choice }\end{array}$ & $\mathrm{x}$ & $\mathrm{x}$ & $\mathrm{x}$ & & & & & \\
\hline 2.2 & Material preparation and characterization before irradiations & & & $\mathrm{x}$ & $\mathrm{x}$ & $\mathrm{x}$ & $\mathrm{x}$ & $\mathrm{x}$ & \\
\hline 2.3 & Initial gamma irradiations & & & $\mathrm{x}$ & $\mathrm{x}$ & & & & \\
\hline 2.4 & Post-irradiation material characterization & & & & $\mathrm{x}$ & $\mathrm{x}$ & $\mathrm{x}$ & $\mathrm{x}$ & \\
\hline 2.5 & $\begin{array}{c}\text { Initial description of radiolytic degradation mechanism based on } \\
\text { the correlation between gas composition data and material } \\
\text { surface changes after irradiation }\end{array}$ & & & & $\mathrm{x}$ & & & & \\
\hline 2.6 & Multi-dimensional irradiation test matrix & & & & $\mathrm{x}$ & $\mathrm{x}$ & $\mathrm{x}$ & $\mathrm{x}$ & $\mathrm{x}$ \\
\hline 2.7 & $\begin{array}{c}\text { Predictive description of radiolytic degradation chemistry inside } \\
\text { storage canister }\end{array}$ & & & & & $\mathrm{x}$ & $\mathrm{x}$ & $\mathrm{x}$ & $\mathrm{X}$ \\
\hline
\end{tabular}




\section{SCHEDULE (SRNL)}

\begin{tabular}{|c|c|c|c|c|c|c|c|c|c|}
\hline \multirow{2}{*}{ Activity } & \multirow{2}{*}{ Description } & \multicolumn{4}{|c|}{ FY18 } & \multicolumn{4}{|c|}{ FY19 } \\
\hline & & 1 & 2 & 3 & 4 & 1 & 2 & 3 & 4 \\
\hline 2.1 & $\begin{array}{l}\text { Experimental design setup and approvals: vessels / heating } \\
\text { apparatus/ gas sampling }\end{array}$ & $\mathrm{x}$ & $\mathrm{x}$ & $\mathrm{x}$ & $\mathrm{x}$ & & & & \\
\hline 2.2 & $\begin{array}{l}\text { Develop test matrix for powder studies } \\
\text { Procure and analyze powders }\end{array}$ & & $\mathrm{x}$ & $\mathrm{x}$ & $\mathrm{x}$ & & & & \\
\hline 2.3 & Sample preparation and conditioning (powders) & & & $\mathrm{x}$ & $\mathrm{x}$ & $\mathrm{x}$ & & & \\
\hline 2.4 & $\begin{array}{l}\text { Initial gamma irradiations (powders) - determine baseline } \mathrm{H}_{2} \text { gas } \\
\text { yields for ideal storage conditions }\end{array}$ & & & & $\mathrm{x}$ & $\mathrm{x}$ & $\mathrm{x}$ & & \\
\hline 2.5 & $\begin{array}{c}\text { Perform multi-dimensional irradiation test matrix (powders) } \\
\text { Determine gas yields with temperature and atmosphere variables }\end{array}$ & & & & $\mathrm{x}$ & $\mathrm{x}$ & $\mathrm{x}$ & $x$ & \\
\hline 2.6 & $\begin{array}{l}\text { Develop a reduced test matrix for coupons which focuses on film } \\
\text { thickness and dominant parameters as determined from powder } \\
\text { results }\end{array}$ & & & & & & $\mathrm{x}$ & $\mathrm{x}$ & \\
\hline 2.7 & Irradiation of coupons using tailored matrix & & & & & & $x$ & $\mathrm{x}$ & $\mathrm{x}$ \\
\hline 2.8 & Document/report & & & & & & & $\mathrm{x}$ & $\mathrm{x}$ \\
\hline
\end{tabular}




\section{REFERENCES}

(1) Kim, Y. S.; Hofman, G. L.; Robinson, A. B.; Snelgrove, J. L.; Hanan, N. Oxidation of Aluminium Alloy Cladding for Research and Test Reactor Fuel. J. Nucl. Mat., 2008, 378, 220228.

(2) Corrosion of Research Reactor Aluminium Clad Spent Nuclear Fuel in Water. IAEA-TECDOC-1637, 2009.

(3) Wittman, R. Radiolysis Model Sensitivity Analysis for a Used Fuel Storage Canister. FCRD-UFD-2013-000357, 2013.

(4) Wittman, R. S.; Hanson, B. D. Radiolysis Model Analysis for a Used Fuel Storage Canister. IHLRWM, 2015.

(5) Elliot, A. J.; Bartels, D. M. The Reaction Set, Rate Constants and G-Values for the Simulation of the Radiolysis of Light Water Over the Range $20^{\circ}$ to $350^{\circ} \mathrm{C}$ Based on Information Available in 2008. AECL Nuclear Platform Research and Development - Report 153-127160-450-001. 2009.

(6) $\mathrm{Hu}, \mathrm{T}$. A. Improved Model for Hydrogen Generation Rate of Radioactive Waste at the Hanford Site. Nucl. Tech., 2012, 178, 39-54.

(7) Morco, R. P.; Joseph, J. M.; Hall, D. S.; Medri, C.; Shoesmith, D. W.; Wren, C. J. Modelling of Radiolytic Production of $\mathrm{HNO}_{3}$ Relevant to Corosion of a Used Fuel Container in Deep Geological Repository Environments. Corros. Eng. Sci. Tech., 2017, 52, 141-147.

(8) Kekki, T.; Zilliacus, R. Formation of Nitric Acid During High Gamma Dose Radiation. VTT-R-00774-11, 2011.

(9) Etoh, Y.; Karasawa, H.; Ide, E.; Sakagami, M.; Yasuda, T. Radiolysis of $\mathrm{N}_{2}-\mathrm{H}_{2} \mathrm{O}$ Systems. $J$. Nucl. Sci. Tech., 1987, 24, 672-674.

(10) Bonin, B.; Colin, M.; Dutfoy, A. Pressure Building During the Early States of Gas Production in a Radioactive Waste Repository. J. Nucl. Mater., 2000, 281, 1-14.

(11) Gangloff, R. P.; Somerday, B. P. Gaseous Hydrogen Embrittlement of Materials in Energy Technologies, Volume 1 - the Problem, its Characterization and Effects on Particular Alloy Classes. Elsevier New York, 2012.

(12) Ambat, R.; Dwaarakadasa, E. S. Effect of Hydrogen in Aluminium and Aluminium Alloys: A Review. Bull. Mater. Sci., 1996, 19, 103-114.

(13) Lu, Gang; Kaxiras, E. Hydrogen Embrittlement of Aluminum: The Crucial Role of Vacancies. Phys. Rev. Let., 2005, 94, 155501-155503.

(14) Elliot, A. J.; Bartels, D. M. The Reaction Set, Rate Constants and G-Values for the Simulation of the Radiolysis of Light Water Over the Range $20^{\circ}$ to $350^{\circ} \mathrm{C}$ Based on Information Available in 2008. AECL.

(15) Buxton, G. V. Nanosecond Pulse Radiolysis of Aqueous Solutions Containing Proton and Hydroxyl Radical Scavengers. Proc. R. Soc. London, Ser. A 1972, 328, 9-21. 